\title{
Estructuras de disyunción columnar en lavas asociadas al Complejo Volcánico Nevado del Ruíz (Colombia): facies, dimensiones y geometría
}

\author{
Yuly Paola Rave-Bonilla ${ }^{1 *}$; John J. Sánchez ${ }^{2}$
}

Forma de citar: Rave-Bonilla, Y.P.; Sánchez, J.J. (2021). Estructuras de disyunción columnar en lavas asociadas al Complejo Volcánico Nevado del Ruíz (Colombia): facies, dimensiones y geometría. Boletín de Geología, 43(2), 45-62. https://doi.org/10.18273/revbol.v43n2-2021003

\begin{abstract}
Resumen
Asociados al Complejo Volcánico Nevado del Ruiz (CVNR) se encuentran varios flujos de lavas con estructuras de disyunción columnar formadas por el régimen físico de enfriamiento. Estos son de interés tanto para el campo de la volcanología como del geoturismo, especialmente para el Geoparque Volcán del Ruiz aspirante a reconocimiento UNESCO, dado que, no solo brindan información sobre los mecanismos de flujo y enfriamiento de las lavas, que a su vez tienen implicaciones en la permeabilidad aprovechable por los fluidos hidrotermales, sino que también hacen parte de los principales atractivos geoturísticos a nivel mundial. En este trabajo se caracterizan las facies de disyunción presentes en cuatro afloramientos ubicados en el flanco noreste del CVNR sobre la vía Manizales - Murillo. De cada afloramiento se realiza una descripción tanto de la morfología del emplazamiento, con base en la fotointerpretación y las observaciones de campo, como de los patrones poligonales, y se determinan las dimensiones de las columnas y sus rasgos menores identificables. Además, se caracterizan macroscópica y microscópicamente las muestras tomadas en cada afloramiento y se establecen sus características texturales y mineralógicas. Como resultado se confirma la composición predominantemente andesítica con presencia de fenocristales euhedrales de plagioclasas (andesina y oligoclasa) de hasta $4 \mathrm{~mm}$ y se determina que las columnas tienen dimensiones de 1,3 $\mathrm{m}$ de ancho y $3 \mathrm{~m}$ de alto en promedio, con estrías separadas por 12,6 cm en promedio aproximadamente y formas poligonales predominantemente de cuatro lados. A partir de los rasgos y características observados, se concluye que estas lavas tuvieron un proceso de enfriamiento rápido y complejo en el que se requirió una alta cantidad de energía, incluyendo disipación de calor y energía deformacional, y que además han sido afectadas por procesos meteorizantes y erosivos intensos.
\end{abstract}

Palabras clave: Disyunción columnar; Mecanismos de enfriamiento; Formas poligonales; Lava; Energía.

\section{Columnar jointing structures in lavas from the Nevado del Ruiz Volcanic Complex (Colombia): Facies, dimensions and geometry}

\begin{abstract}
Associated with the Nevado del Ruiz Volcanic Complex (NRVC), there are several lava flows with columnar jointing structures that were formed by the physical cooling regime. These joints, of interest to the volcanology and geoturism, specially for the Volcán del Ruiz Geopark, candidate to UNESCO recognition, not only because they have significance to the understanding of flow and cooling mechanisms which in turn have implications on the permeability to geothermal fluids, but also because they are attractive structures for geoturism around the world. In this work, the jointing facies in lavas from four sites along the road between Manizales and Murillo on the northeastern flank of NRVC are characterized. From each outcrop a description is presented in terms of the morphology, using aerial photographs and field observations, and by documenting the dimensions and geometries of joints and their identifiable minor structures. Also, the macroscopic and microscopic characteristics of rock samples from each site allowed the textural features and modal mineralogy to be established. The andesite composition of all samples is confirmed, with euhedral plagioclase (andesine and oligoclase) crystals of up to $4 \mathrm{~mm}$ in size. It was also determined that the columns have average dimensions of $1.3 \mathrm{~m}$ width, $3 \mathrm{~m}$ high, with striae separated by an average of $12.6 \mathrm{~cm}$, and polygonal shapes with predominantly four sides. From these observed features it is concluded that these lavas underwent a relatively quick but nonetheless complex cooling process that involved a large amount of energy, including heat dissipation and deformational energy, and also that many primary features in the emplacements have most likely been affected by intense weathering and erosion.
\end{abstract}

Keywords: Columnar jointing; Cooling mechanisms; Polygonal shapes; Lava; Energy.

${ }^{1}$ Departamento de Geociencias, Universidad Nacional de Colombia, Bogotá, Colombia. (*) ypraveb@unal.edu.co ${ }^{2}$ Departamento de Geociencias y Medio Ambiente, Universidad Nacional de Colombia, Medellín, Colombia. jjsanchezag@unal.edu.co 


\section{Introducción}

El Complejo Volcánico Nevado del Ruiz (CVNR) incluye el volcán Nevado del Ruiz, un volcán compuesto de composición andesítica que se encuentra en la región media de la Cordillera Central de Colombia entre los departamentos de Caldas y Tolima, haciendo parte de la Provincia Volcano-Tectónica San Diego - Cerro Machín (Martínez et al., 2014; Murcia et al., 2019) (Figura 1). Su historia eruptiva comenzó hace 1,8 Ma ( $\mathrm{K}$ - Ar) (Thouret, 1990) y se divide en cuatro períodos eruptivos, siendo del más antiguo al más reciente, los siguientes: Periodo Eruptivo PRE - Ruiz (Pre-Ruiz), Primer Periodo Eruptivo Ruiz (PER), Periodo Eruptivo Intermedio Ruiz (INTER) y Segundo Periodo Eruptivo Ruiz (SER) (período que continúa actualmente) (Martínez et al., 2014; Ceballos-Hernández et al.,
2020). Sobre la vía Murillo - Manizales, en el sector nororiental del CVNR se encuentran emplazamientos de flujos de lava con estructuras de disyunción columnar formadas durante efusiones de los períodos PRE - Ruiz, PER y SER de afinidad calcoalcalina cuya composición, según análisis geoquímicos de roca total de Rayo (2012), se encuentra entre andesítica y dacítica $\left(\mathrm{SiO}_{2}\right.$ entre 54,5 y 66,6 wt.\%, de álcalis $\left(\mathrm{Na}_{2} \mathrm{O}+\mathrm{K}_{2} \mathrm{O}\right)$ entre 4,0 y 7,2 wt.\%, un contenido máximo de $\mathrm{MgO}$ de 5,5 wt.\%). En el país han sido poco documentadas este tipo de estructuras, siendo el trabajo de Flórez (2017) uno de los escasos estudios que en este caso realiza una descripción detallada de seis sitios de rocas volcánicas con diaclasas columnares en varias localidades de Colombia. Sin embargo, los depósitos asociados al CVNR con este tipo de estructuras no se han analizado en detalle.

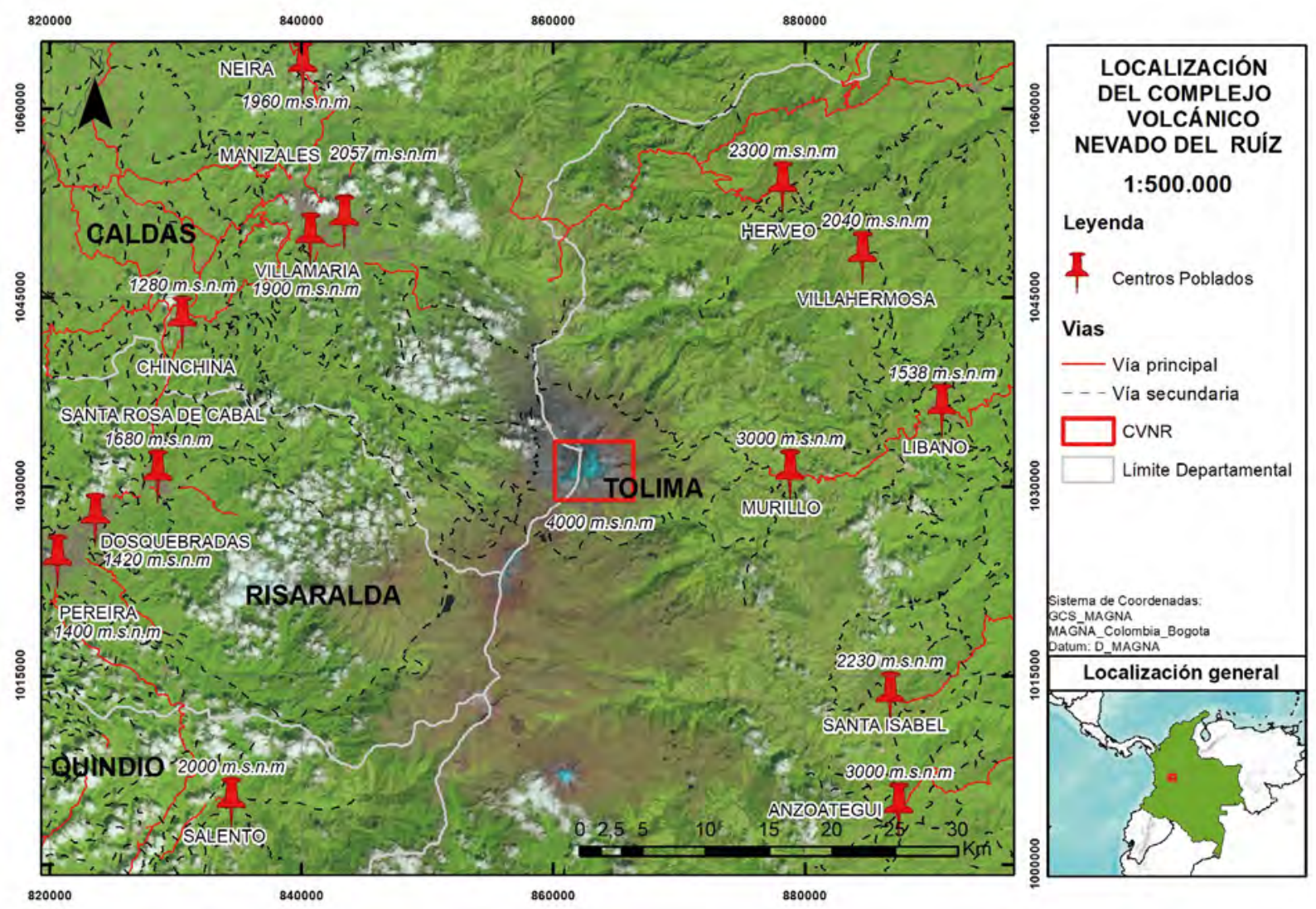

Figura 1. Ubicación del Complejo Volcánico Nevado del Ruiz. Imagen Sentinel A2 de USGS https:/earthexplorer.usgs.gov/. Datos de municipios tomados de Instituto Geográfico Agustín Codazzi (IGAC).

Las estructuras de disyunción columnar se deben a los esfuerzos de contracción de cuerpos de magma que se están enfriando y solidificando, lo cual genera fracturas, que se propagan desde el exterior hacia el interior del cuerpo (DeGraff y Aydin, 1987); la propagación lateral y vertical de las diaclasas desarrolla columnas prismáticas perpendiculares a la dirección de mayor pérdida de calor, cuyos polígonos 
comúnmente observados en vista de planta (Sánchez y Osorio, 2008) tienen un promedio de orden poligonal de seis lados, entendida como la forma que requiere menos energía, según lo concluido por Hetényi et al. (2012) en su estudio de 50 sitios diferentes en todo el espectro composicional, de rocas máficas a félsicas, en cuatro regiones europeas, a la cual se asocian la mejor madurez y tasa de enfriamiento lento. La composición de las lavas con disyunción varía de riolítica a basáltica existiendo una correlación positiva entre el contenido de sílice y el tamaño de las columnas, siendo las columnas de flujos félsicos más robustas que las de flujos máficos (Hetényi et al., 2012).

En el presente trabajo se realiza una descripción detallada de cuatro afloramientos de emplazamientos de flujos de lava con disyunción columnar que se encuentran en el flanco noreste del Nevado del Ruiz en la vía Murillo - Manizales (Figura 2), registrando las dimensiones y morfologías del emplazamiento y de las columnas, la presencia de facies identificadas como entabladura y columnata e indicadores de la dirección de enfriamiento del flujo y los puntos de origen de las fracturas formadas. Adicionalmente, se incluye una caracterización macroscópica, y un análisis petrográfico de las muestras de cada afloramiento, todo con el fin de identificar las posibles condiciones generales de enfriamiento que dieron lugar a la formación de diaclasas columnares en estos emplazamientos de lava localizados. Así, esta investigación aporta datos e información más detallada con miras al entendimiento de uno de los fenómenos más complejos del volcanismo: el régimen de emplazamiento y enfriamiento de los flujos de lava.
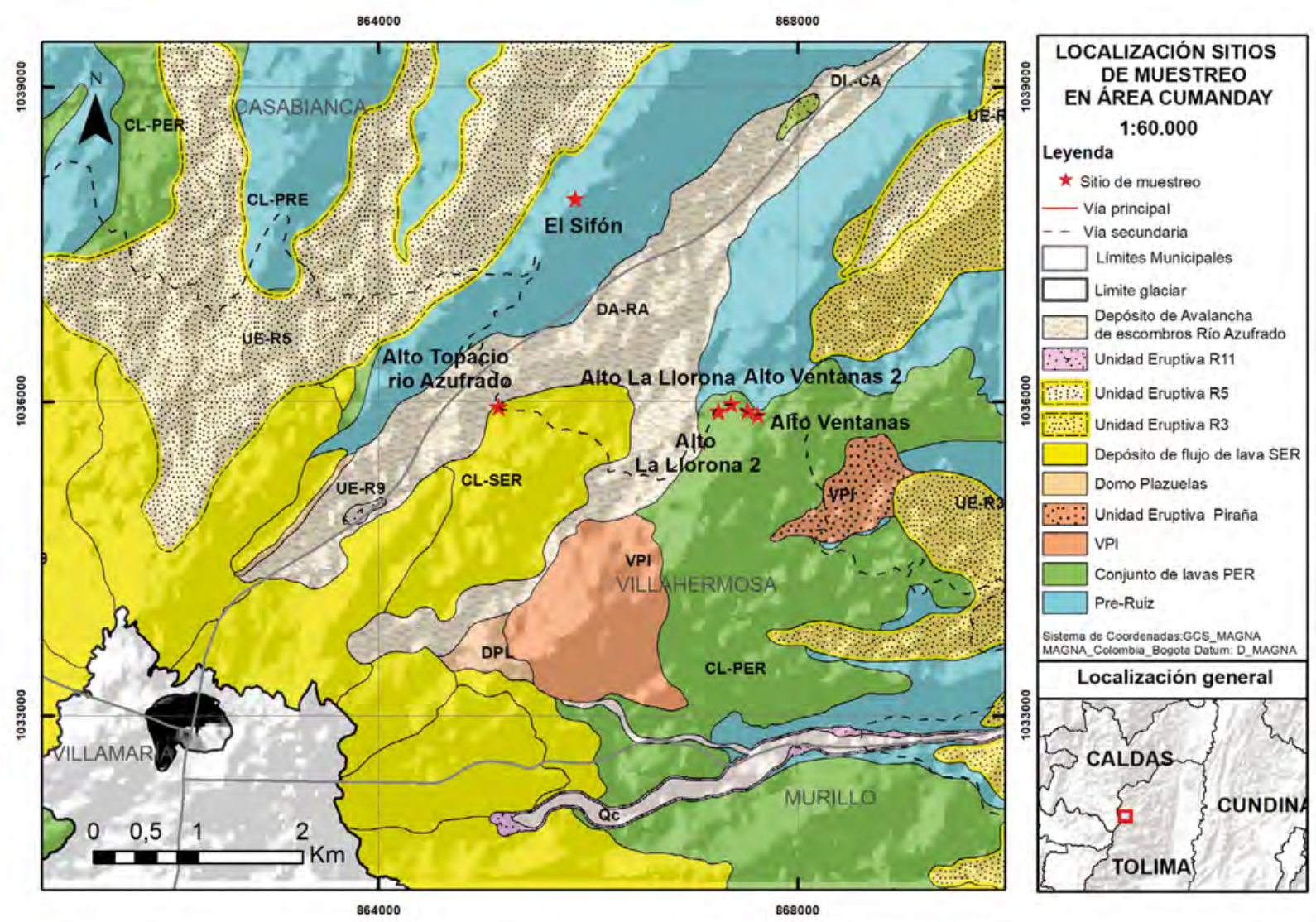

Figura 2. Localización de sitios de muestreo en el mapa geológico del área noreste del Complejo Volcánico Nevado del Ruiz. Mapa tomado y modificado de: Cartografía base Mapa geológico del área Cumanday - SGC (Martínez et al., 2014). Datos de municipios tomados del Instituto Geográfico Agustín Codazzi. 


\section{Marco teórico}

Las diaclasas columnares son redes de fracturas de tensión interconectadas que dividen un cuerpo sólido en prismas o columnas con ejes paralelos y secciones transversales poligonales (DeGraff y Aydin, 1987), las cuales, aunque suelen ser hexagonales, también se encuentran con configuraciones de tres y hasta ocho lados (Sánchez y Osorio, 2008; Goehring y Morris, 2008) y pueden formarse en flujos de lavas o depósitos de corrientes de densidad piroclástica en todo el espectro composicional ultramáfico - riolítico (Wright et al., 2011), en un amplio rango de ambientes desde subaéreos a subglaciales (Phillips et al., 2013). Por otro lado, autores como Weinberger y Burg (2019) han descrito este tipo de estructuras en rocas sedimentarias como arenitas, lodolitas y arcillolitas y en rocas meta calcáreas, asociadas a un proceso de desecación.

La formación de diaclasas columnares se relaciona al decrecimiento en volumen de un cuerpo (Weinberger y Burg, 2019), en el caso de los cuerpos de lava, por efectos de contracción térmica, lo que crea esfuerzos de tensión dentro del mismo (DeGraff y Aydin, 1987). Según Müller (1998), Saemundsson (1970) y Phillips et al. (2013), su formación necesariamente está relacionada con una entrada de agua que fluye durante tiempos considerables (meses y años) por encima del cuerpo de lava e interviene drásticamente en su enfriamiento (Müller, 1998).

Elnivel de esfuerzo y energíanecesarios para generaruna diaclasa entre dos puntos es inversamente proporcional al número de caras del prisma, así un número elevado de caras es más eficiente energéticamente (Spry, 1962). Este esfuerzo debido a la contracción térmica puede acumularse una vez la temperatura cae por debajo de la temperatura de comportamiento elástico, conocida como la temperatura de transición del vidrio $(\mathrm{Tg})$ (Pollard y Aydin, 1988). Algunos modelos clásicos proponen una capa plana en la que el enfriamiento inicia desde la superficie, así las fracturas solo pueden ocurrir en materiales frágiles y las diaclasas se propagan progresivamente hacia adentro siguiendo la migración de la isoterma que define $\mathrm{Tg}$ (Pollard y Aydin, 1988). El diaclasamiento ocurre cuando el esfuerzo excede la fuerza de tensión del material probablemente en un estado subsólido, en temperaturas calculadas alrededor de $900^{\circ} \mathrm{C}$ en basaltos (Budkewitsch y Robin, 1994).

El espaciamiento entre las columnas depende inversamente de la tasa de enfriamiento ( $\partial \mathrm{T} / \partial \mathrm{t})$ en el momento y lugar en que inicia la fractura
(Grossenbacher y McDuffie, 1995). Un proceso de enfriamiento lento produce columnas más gruesas y robustas que las que produce un enfriamiento rápido. Además, el contenido de vidrio en la roca es proporcional a la tasa de enfriamiento, siendo lenta cuando hay una alta cristalinidad y rápida cuando hay alto contenido de vidrio (Grossenbacher y McDuffie, 1995). Adicional a ello, el crecimiento de las columnas es perpendicular a la superficie de enfriamiento, la cual suele coincidir con la superficie de flujo, por lo que, su disposición suele ser vertical a subvertical, aunque otras orientaciones de estas estructuras han sido también documentadas (Müller, 1998).

Algunos casos bien documentados de emplazamientos de flujos de lava muestran que una unidad ideal de flujo de lava incluye cuatro secciones características, que, de la base al tope, son: columnata inferior, entabladura, columnata superior y un tope de flujo vesicular (Figura 3). En las columnatas inferior y superior se observan columnas regulares con lados casi planares, mientras que en la entabladura las columnas son irregulares, usualmente con formas y orientaciones variables, desordenadas y de apariencia curva; el tope del flujo es delgado y con textura de brecha (Spry, 1962). Las principales subdivisiones pueden no estar desarrolladas de forma equitativa y pueden tener diferentes espesores e incluso una de ellas puede no estar presente (Winter, 2014). Las columnatas se forman durante enfriamiento más o menos regular por disipación de calor desde el interior del flujo hacia la periferia, que está formada por el contacto flujo - atmósfera (o agua, o hielo, dependiendo del medio de emplazamiento) en el techo y flujo - suelo en la base. Se ha atribuido la diferencia en configuración entre la columnata inferior y superior a diferencia en tasa de disipación de calor entre la base y el techo del flujo, ya que en el primer caso la disipación de calor conductiva es tres veces más lenta que la disipación de calor convectiva y radiante que caracterizaría al techo (Schmincke, 2004). De otra parte, la variabilidad en inclinación (desde horizontal hasta vertical) de las columnas en la columnata inferior se ha atribuido a enfriamiento del flujo contra las paredes y el lecho del valle en el cual ocurre el emplazamiento (Scrope, 1825).

La presencia de la entabladura se ha explicado como el producto de una tasa de enfriamiento más elevada en la parte superior del flujo de lava (Jerram y Petford, 2011) debido al paso de agua entre las diaclasas que conectan el interior del cuerpo de lava con la superficie (Saemundsson, 1970; Long y Wood, 1986). Según los estudios de autores como Saemundsson (1970), en 
flujos de basaltos interglaciares en Islandia, o Phillips et al. (2013), en los basaltos columnares de Staffa en Escocia, la formación de la facies entabladura representa la interacción entre dos conjuntos diferentes de diaclasas, uno de ellos probablemente influenciado por la interacción del cuerpo de lava con agua.

En las columnas, con frecuencia es posible observar estructuras denominadas estrías y estructuras plumosas (DeGraff y Aydin, 1987) que indican dos aspectos de la historia de formación de las diaclasas: el gradiente térmico y la dirección de propagación de las fracturas. Las estrías aparecen como bandas en las caras de las columnas, tienen disposición normal a los ejes de columnas, pueden ser muy regulares, pero también discontinuas y paralelas, y representan la propagación episódica del crecimiento de las diaclasas (Spry, 1962). El espesor de las estrías se relaciona de forma inversa con el gradiente térmico local (Grossenbacher y McDuffie, 1995) y es también consistente con la tasa de enfriamiento advectivo que se debe a la presencia de agua dentro de las fracturas (Phillips et al., 2013). Las estructuras plumosas tienen forma de abanicos que se expanden a lo largo de un eje que contiene un punto de origen de fractura, formadas cuando el rompimiento se propaga en la superficie de un material cargado de esfuerzo de tensión pero que inicialmente tiene un esfuerzo compresivo residual (DeGraff y Aydin, 1987). Las curvas en los abanicos indican las posiciones sucesivas del frente de fractura y muestran su propagación iniciando en el eje de la pluma, en el centro de una banda donde el esfuerzo de tensión es mayor (DeGraff y Aydin, 1987) (Figura 3), aunque también pueden estar localizadas en otras posiciones a lo largo de una estría.

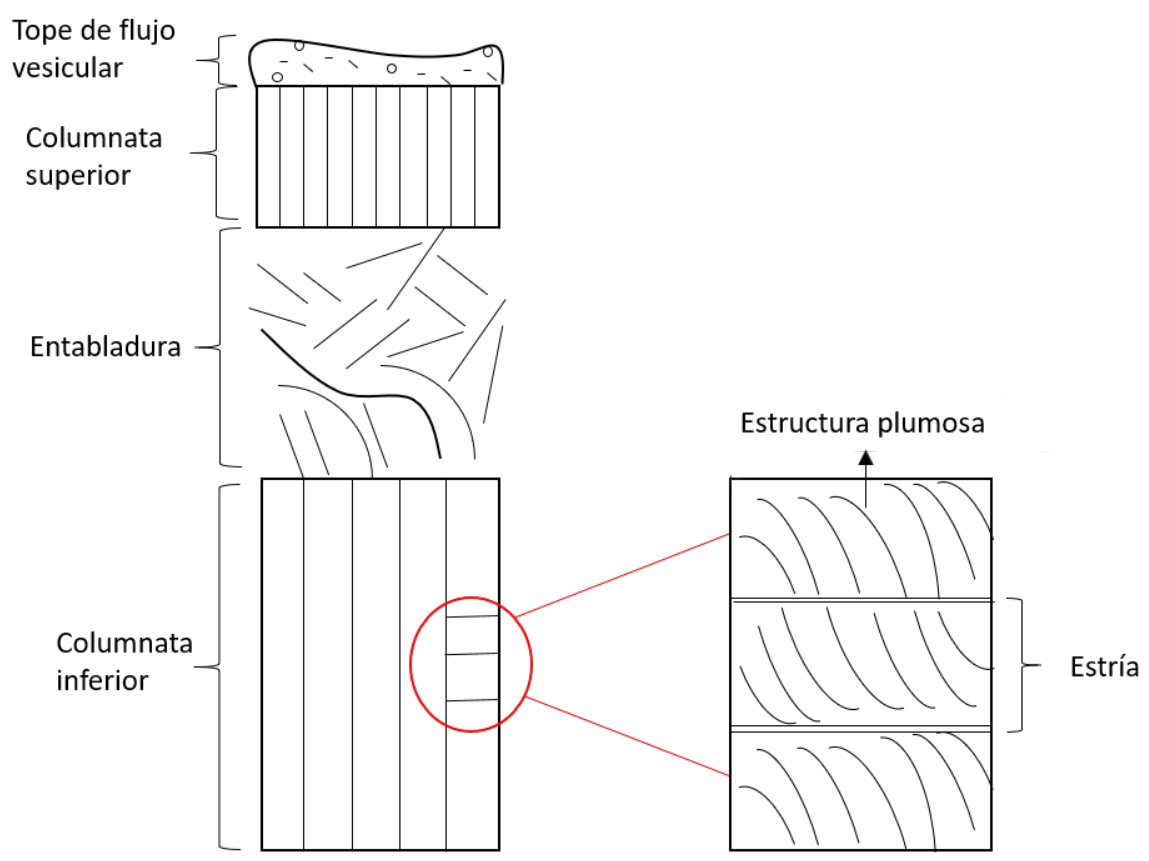

Figura 3. Facies y estructuras características de lavas con disyunción columnar (basado en Long y Wood (1986) y Li y Liu (2020)).

Las dimensiones más importantes, descritas regularmente para las estructuras de disyunción columnar son: el alto (l), y ancho de las columnas $(W f)$, el diámetro de las columnas o los polígonos (d), el ancho de las estrías $(W b)$ y la relación de aspecto $l / d$, basado en la convención de DeGraff y Aydin (1987) (Figura 4). 

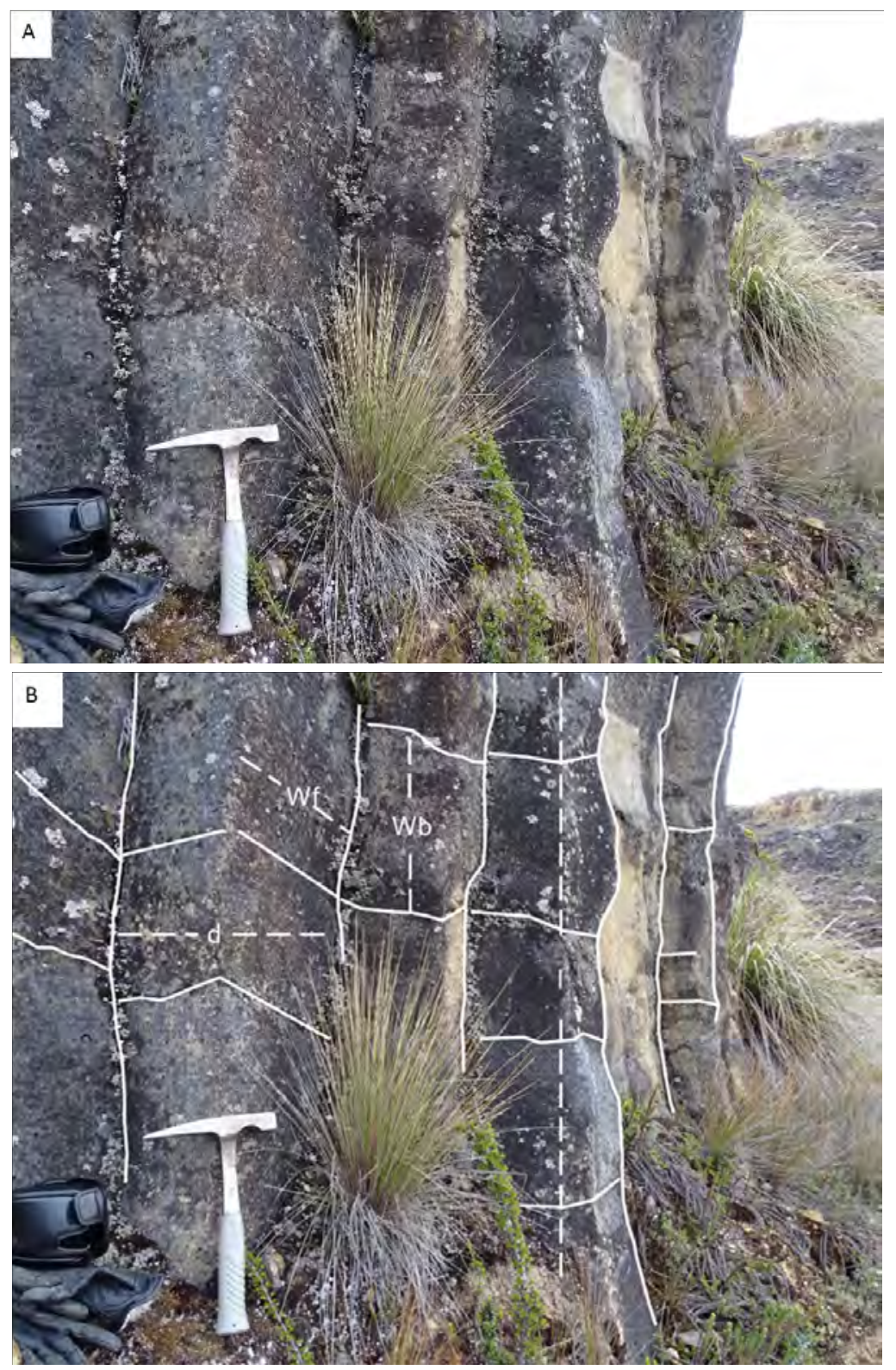

Figura 4. A. Columnas y estrías del sitio Alto Topacio - Río Azufrado. B. Dimensiones de las columnas: longitud (column length, $l$ ), ancho de cara de columna (columna - face width, $W f$ ), diámetro de columna (diámetro de polígonos en vista de planta) (column diameter, $d$ ) y espesor de las estrías (band width, $W b$ ) según convención de DeGraff y Aydin (1987). Sitio Alto Topacio - Río Azufrado (coordenadas: 865150.46, 1035945.87). Dimensión del martillo 27 cm.

\section{Metodología}

\section{Fotointerpretación}

Se interpretaron siete fotografías aéreas del área de estudio, solicitadas en el Instituto Geográfico Agustín Codazzi, usando estereoscopios de espejos. El análisis incluyó el reconocimiento de la morfología de los emplazamientos de lava en el área, particularmente aquellos directamente observados en campo, determinación de sus dimensiones, estimación aproximada, por caracterización visual, de la dirección del flujo y la morfología y pendiente del valle por el que ocurrió el emplazamiento. Los depósitos son lobulares, aparentemente emitidos desde la misma fuente (VNR), hacia el noreste, alcanzando distancias entre 0,7 y $11 \mathrm{~km}$ de largo. Para enfatizar algunos rasgos, aumentar la resolución y facilitar las medidas, se realizó la superposición de tres imágenes aéreas UAVSAR con resolución de $12 \mathrm{~m} /$ pixel de diferentes vuelos y con variables condiciones de iluminación 
tomadas por el JPL en 2014 sobre las imágenes de Google Earth ${ }^{\mathrm{TM}}$ con cobertura en todo el CVNR. Las imágenes UAVSAR ColVol_09105_14038, ColVol_27004_14038 y ColVol_19100_15021, fueron descargadas desde el sitio web de Alaska SAR Facility.

\section{Trabajo de campo y análisis macroscópico}

Se realizaron tres visitas a la zona de campo sobre la vía Murillo - Manizales en el costado noreste del CVNR, seleccionando cuatro afloramientos con estructuras evidentes de disyunción columnar y en lo posible, facies observables. Se realizaron inspecciones mesoscópicas para diferenciar las facies presentes (entabladura: facies superior sin orientación definida, columnata: facies inferior con columnas paralelas y bien formadas), y para definir la morfología de las columnas, seguida por una observación detallada de estructuras más finas como estrías, estructuras plumosas en las caras de las columnas o anillos en los cortes transversales, la forma y número de lados de los polígonos y el espacio entre columnas y relleno entre las mismas. Se determinaron todas las dimensiones posibles, haciendo uso de cintas métricas y brújulas convencionales, tanto el espesor local del emplazamiento y la altura y el ancho del frente del flujo, como el alto de entabladura y columnata en caso de estar presentes, el alto de las columnas, ancho de sus caras, diámetro del polígono del corte transversal, el ancho de las estrías, la magnitud de las estructuras plumosas y el espacio entre las columnas. Por último, en las muestras de mano se llevó a cabo de forma preliminar un análisis macroscópico teniendo en cuenta el color, el tamaño de los fenocristales y la orientación de estos, el porcentaje de vesicularidad y cristalinidad, y el análisis mineralógico modal general.

\section{Procesamiento estadístico}

Todos los datos de dimensiones determinados en campo fueron tabulados para el cálculo de medidas de tendencia central como la media y la mediana, tomando la mediana como medida de tendencia central más apropiada para una muestra cuyos datos no difieren drásticamente entre sí y que cuenta con algunos datos atípicos (Levin y Rubin, 2004). Las medidas de dispersión, específicamente la desviación estándar, se calculan usando la corrección de Bessel, cambiando el número de observaciones de la muestra $n$ por $n-1$. Los datos extremos fueron analizados a partir de la distribución de los datos entre cuartiles. El rango intercuartílico fue usado en la construcción de diagramas de caja y bigote para visualizar la variabilidad y distribución de las variables analizadas. Además, se realizaron representaciones con gráficas de barras del conjunto de datos obtenido para comparar la información entre los diferentes sitios y asociarla con los resultados del análisis petrográfico.

\section{Análisis petrográfico}

En los laboratorios de petrografía de la Universidad Nacional de Colombia, sede Bogotá, se separaron pequeñas porciones de las muestras de mano, inicialmente con la maquina cortadora Geocut Metkon y la sierra Ingram i35, hasta alcanzar un grosor de 5 $\mathrm{mm}$ y luego se redujeron en desbastadora Ingram 400 hasta máximo $2 \mathrm{~mm}$ de grosor. Por último, se usó abrasivo de carburo de silicio de calibres 600 y 1200 hasta disminuir su grosor a $0,03 \mathrm{~mm}$, apropiado para la transmisión de luz.

El análisis de las secciones se realizó con un microscopio binocular Motic BA310 POL con un aumento base de $5 \mathrm{x}$ en el que se realizó la identificación del tipo de masa fundamental y la determinación de la moda mineral a partir de la selección de 10 puntos al azar de cada sección delgada en la que se calculó el porcentaje de cada mineral presente entre los fenocristales y luego se normalizaron los minerales indicativos para la clasificación de rocas ígneas (cuarzo, plagioclasa y feldespato alcalino), además del cálculo del índice de color, la identificación de los tipos de plagioclasa presentes y la estimación del porcentaje de matriz vítrea para clasificar de forma completa las muestras con base en Streckeisen (1979). La plagioclasa y el anfíbol fueron notablemente abundantes y sus dimensiones fueron cuantificadas para dar una mejor idea acerca de las características macroscópicas y microscópicas de la textura.

\section{Resultados}

\section{Morfología de los flujos y estructuras de disyunción}

Una inspección preliminar de los cuatro emplazamientos de lava estudiados, usando estimaciones visuales de fotografías aéreas, reveló dominio de la forma lobular en el frente de los flujos y ápices pronunciados que se adelgazan progresivamente hasta llegar a la fuente. Con base en la morfología del emplazamiento, la dirección de los flujos habría sido hacia al norte y el nororiente. En algunos de los emplazamientos se 
evidencian rasgos erosivos como formas cóncavas y superficies de textura suave (Figura 5).

La combinación de la observación de fotografías aéreas, imágenes UAVSAR y de Google Earth ${ }^{\mathrm{TM}}$ y las comprobaciones de los límites de los flujos de lava en campo, permitió definir detalles morfológicos en cada uno de los emplazamientos. El sitio Alto Topacio - Río Azufrado muestra una morfología compleja en la vista de mapa, con apariencia escalonada y con tres a cuatro lóbulos cerca de su parte distal, la cual tiene un ancho de $0,7 \mathrm{~km}$. Aunque no es claro cuál es exactamente la fuente de este flujo, se estima una longitud total de $5 \mathrm{~km}$ con base en el mapa geológico de Martínez et al. (2014) y con el espesor medido en campo de $15 \mathrm{~m}$, su volumen aproximado sería $0,05 \mathrm{~km}^{3}$. El flujo en el que se encuentran los sitios Alto de Ventanas y Alto La
Llorona muestra también una morfología compleja en la vista de mapa, con aspecto escalonado y al menos tres diferentes lóbulos con ancho máximo de 1,5 km en su parte distal. La longitud probable de este flujo es de $8 \mathrm{~km}$ y el espesor estimado de este flujo según las medidas tomadas en campo sería de $50 \mathrm{~m}$, según esto el volumen aproximado es de $0,6 \mathrm{~km}^{3}$; valor que podría ser un subestimado debido a las dificultades de acceso que impedían medir un espesor más aproximado. El flujo en el que se encuentra el afloramiento de El Sifón muestra una forma más simple en la vista de mapa con morfología baja que no permite determinar su ancho máximo. La mayor longitud estimada con base en el mapa geológico es de $11 \mathrm{~km}$ y un ancho de $2 \mathrm{~km}$ y según el mapa topográfico se aprecian al menos $300 \mathrm{~m}$ de espesor, lo que sugiere un volumen aproximado de flujo de $6 \mathrm{~km}^{3}$

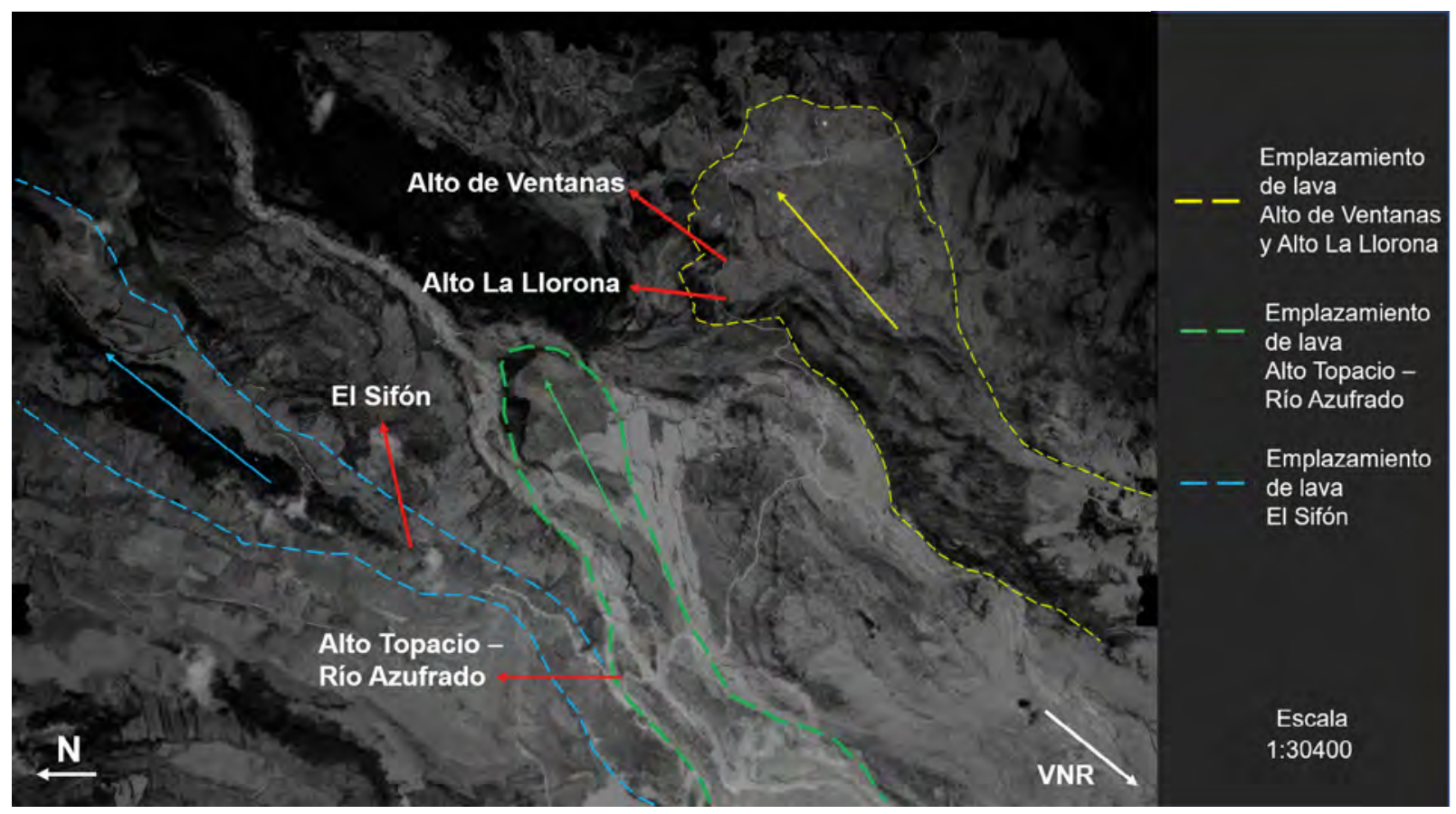

Figura 5. Fotografía aérea regional (IGAC). Foto No. 26 del vuelo C - 2466 escala 1: 30400.

En cuanto a las dimensiones y características de los afloramientos (Tabla 1), estos tienen en promedio $10 \mathrm{~m}$ de alto y $60 \mathrm{~m}$ de ancho. En algunos casos fue posible observar las facies columnata y entabladura en un mismo afloramiento, mientras que en otros solo fue posible definir una de las facies. Para diferenciar entre las facies se usó como criterio la disposición de las estrías y la forma en que se encuentran orientadas, definiendo la columnata como aquella porción donde las estrías son horizontales a sub horizontales y la entabladura donde estas tienden a ser verticales, curveadas y desordenadas (Figura 6). Las dimensiones de las columnas varían ampliamente entre los emplazamientos (Tabla 1), mientras que las formas poligonales de cuadriláteros y la presencia de estrías paralelas sobre las caras de las columnas es un rasgo común a todos los sitios (Figura 6). 

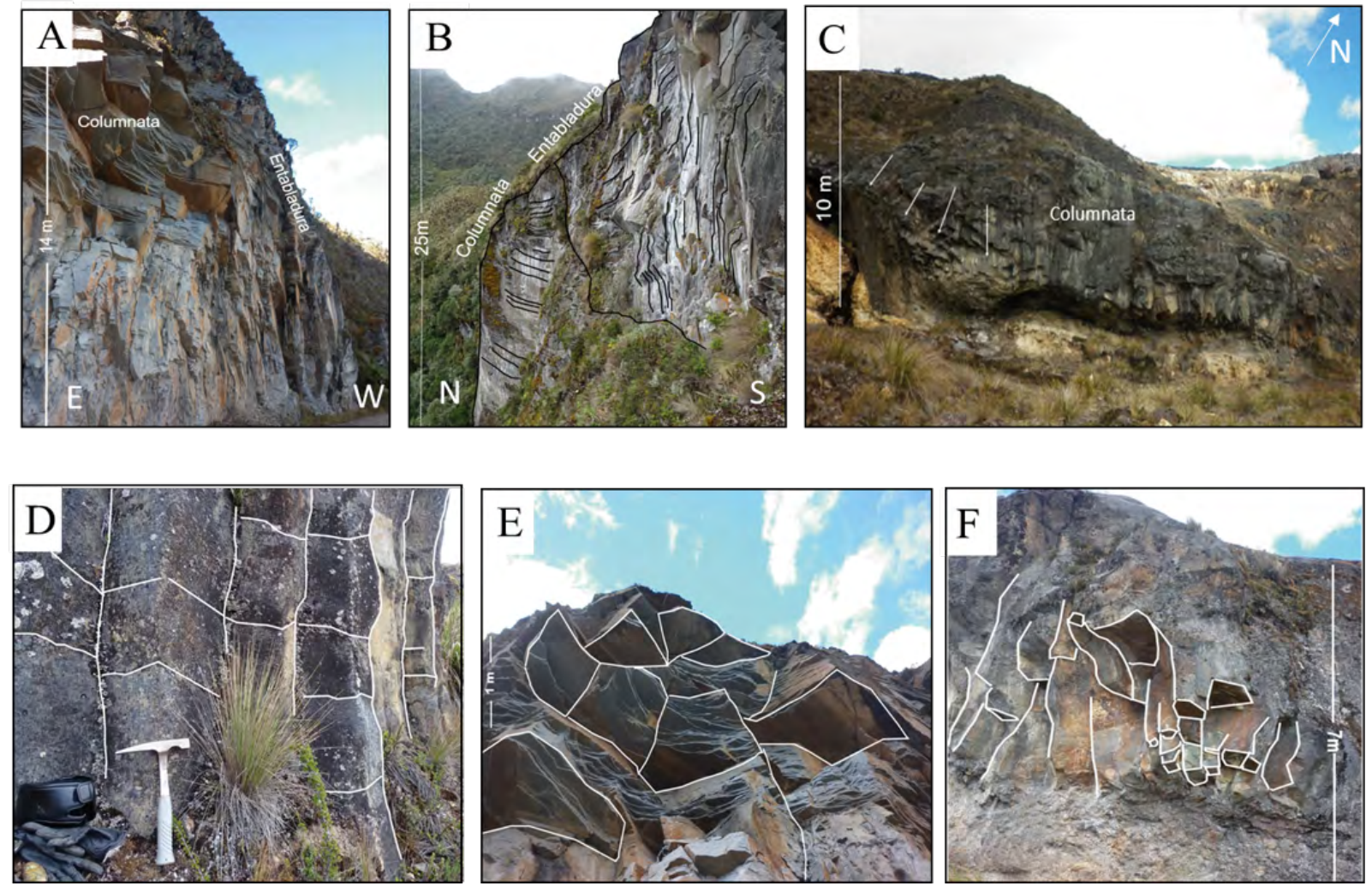

Figura 6. A. Facies de disyunción columnar en el sitio Alto La Llorona. B. Esquema de las facies presentes en el afloramiento Alto de Ventanas. C. Sitio Alto Topacio - Río Azufrado, donde solo se observa la facies columnata. Imágenes y modificaciones propias. D. Estrías paralelas en las caras de las columnas en el sitio Alto Topacio, martillo de $27 \mathrm{~cm}$. E. Formas poligonales en las columnas del sitio Alto La Llorona. F. Columnas con cuadriláteros en los cortes transversales del sitio Alto Topacio - Río Azufrado.

Las muestras de mano examinadas de cada uno de los afloramientos presentaron características muy similares entre ellas: textura porfirítica con cristales de plagioclasa de forma tabular de $\sim 3 \mathrm{~mm}$, representando en promedio el $25 \%$ del volumen de la roca; anfíbol de hasta $3 \mathrm{~mm}$ entre 10 y 15 vol.\% y masa fundamental vítrea de color gris oscuro o negro en hasta 60 vol.\% de la muestra. Además, se encontraron vesículas en un 10 vol.\% o menos y en ocasiones zonas amarillentas asociadas a azufre.

\section{Procesamiento estadístico}

En la Tabla 1 se consignan los datos recolectados en campo para cada sitio y se reportan también las medidas de tendencia central y dispersión de cada caso.

La inspección de los sitios y el análisis de fotografías aéreas e imágenes revela que predomina la morfología de lóbulos y que el par columnata - entabladura no siempre es observable, sin embargo, en los casos en los que estas fueron definidas, la facies columnata comúnmente supera los $11 \mathrm{~m}$ de altura y la entabladura es cercana a $5 \mathrm{~m}$ (Tabla 2). Se encuentra que los parámetros de mayor variabilidad son la longitud y ancho de las columnas y el espesor de las estrías. Las columnas tienden a ser cuasi verticales $\left(73^{\circ} \mathrm{E}\right.$ en promedio) y tienen una media de altura alrededor de $3 \mathrm{~m}$ y de ancho de $1 \mathrm{~m}$; el espacio entre ellas, de orden milimétrico ( $1,8 \mathrm{~mm}$ en promedio) comúnmente se encuentra relleno de material tamaño arcilla, limo, lodo y ocasionalmente agua. En cuanto a las estrías, el espesor promedio es de $12 \mathrm{~cm}$ y su inclinación es hacia el oeste con aproximadamente $24^{\circ}$, con base en la media de las medidas tomadas. Los polígonos que se aprecian en los cortes transversales a las columnas son comúnmente de cuatro lados y las dimensiones de estos lados varían entre $20 \mathrm{~cm}$ a 2,3 m, mientras que la diagonal de los estos cuadriláteros varía entre $43,3 \mathrm{~cm}$ a 2,6 m (Tabla 2). 
Tabla 1. Datos tomados en campo de dimensiones de columnas (longitud, ancho, diámetro) y estrías y medidas de tendencia central y dispersión.

\begin{tabular}{|c|c|c|c|c|}
\hline & Alto de Ventanas & Alto La Llorona & $\begin{array}{c}\text { Alto Topacio - Río } \\
\text { Azufrado } \\
\end{array}$ & El Sifón \\
\hline \multirow[t]{16}{*}{ Longitud de columnas (m) } & 3,0 & 3,5 & 1,30 & 7,0 \\
\hline & 4,0 & 4,0 & 1,25 & 5,0 \\
\hline & 2,5 & 2,5 & 1,60 & 6,0 \\
\hline & 2,0 & 1,0 & 1,60 & 5,0 \\
\hline & 2,0 & 0,7 & 2,00 & 6,5 \\
\hline & & 1,5 & 2,50 & 9,0 \\
\hline & & 2,0 & 2,00 & 8,0 \\
\hline & & & & 5,0 \\
\hline & & & & 4,5 \\
\hline & & & & 6,0 \\
\hline & & & & 4,5 \\
\hline & & & & 5,0 \\
\hline & & & & 6,0 \\
\hline & & & & 4,5 \\
\hline & & & & 4,0 \\
\hline & & & & 5,0 \\
\hline Media & 2,7 & 2,2 & 1,8 & 5,7 \\
\hline Mediana & 2,5 & 2,0 & 1,6 & 5,0 \\
\hline Desviación estándar & 0,8 & 1,2 & 0,4 & 1,3 \\
\hline \multirow[t]{16}{*}{ Ancho de columnas (m) } & 1,7 & 1,0 & 0,40 & 3,0 \\
\hline & 2,0 & 1,5 & 0,30 & 2,0 \\
\hline & 1,2 & 1,3 & 0,50 & 2,5 \\
\hline & 1,0 & 0,8 & 0.35 & 1,5 \\
\hline & 1,6 & 1,0 & 0,25 & 1,5 \\
\hline & & 1,2 & 0,35 & 3,5 \\
\hline & & 0,7 & 0,35 & 3,2 \\
\hline & & & & 2,0 \\
\hline & & & & 1,0 \\
\hline & & & & 2,5 \\
\hline & & & & 2,5 \\
\hline & & & & 2,0 \\
\hline & & & & 1,5 \\
\hline & & & & 2,5 \\
\hline & & & & 2,0 \\
\hline & & & & 2,0 \\
\hline
\end{tabular}


Continuación Tabla 1.

\begin{tabular}{|c|c|c|c|c|}
\hline & Alto de Ventanas & Alto La Llorona & $\begin{array}{c}\text { Alto Topacio - Río } \\
\text { Azufrado }\end{array}$ & El Sifón \\
\hline Media & 1,5 & 1,1 & 0,3 & 2,2 \\
\hline Mediana & 1,6 & 1,0 & 0,4 & 2,0 \\
\hline Desviación estándar & 0,3 & 0,3 & 0,1 & 0,7 \\
\hline \multirow[t]{4}{*}{ Diámetro de polígonos (m) } & 1,8 & 0,18 & 0,65 & 3,5 \\
\hline & 1,5 & 1,5 & 0,15 & 1,8 \\
\hline & 1,1 & 2,9 & 0,5 & 2,7 \\
\hline & & & & 2,3 \\
\hline Media & 1,5 & 1,5 & 0,4 & 2,6 \\
\hline Mediana & 1,5 & 1,5 & 0,5 & 2,5 \\
\hline Desviación estándar & 0,3 & 1,1 & 0,2 & 0,7 \\
\hline \multirow[t]{19}{*}{ Ancho de estrías (cm) } & 2,0 & 10,0 & 25,0 & 17,0 \\
\hline & 2,0 & 8,0 & 35,0 & 30,0 \\
\hline & 3,0 & 8,0 & 26,0 & 15,0 \\
\hline & 4,0 & 11,0 & 30,0 & 14,0 \\
\hline & 5,0 & 9,0 & 38,0 & 16,0 \\
\hline & 3,0 & 14,0 & 13,0 & 13,0 \\
\hline & 4,0 & 3,0 & 20,0 & 15,0 \\
\hline & 10,0 & 5,0 & 9,0 & 10,0 \\
\hline & 10,0 & 4,0 & 7,0 & 12,0 \\
\hline & 4,0 & 8,0 & 17,0 & 13,0 \\
\hline & 3,0 & 12,0 & & 10,0 \\
\hline & 12,0 & 10,0 & & 17,0 \\
\hline & & 12,0 & & \\
\hline & & 7,0 & & \\
\hline & & 3,0 & & \\
\hline & & 4,0 & & \\
\hline & & 6,0 & & \\
\hline & & 10,0 & & \\
\hline & & 10,0 & & \\
\hline Media & 5,2 & 8,1 & 22,0 & 15,2 \\
\hline Mediana & 4,0 & 8,0 & 22,5 & 14,5 \\
\hline Desviación estándar & 3,46 & 3,25 & 10,64 & 5,24 \\
\hline
\end{tabular}


Tabla 2. Comparación de dimensiones, morfologías y facies entre los afloramientos.

\begin{tabular}{|c|c|c|c|c|c|c|c|c|}
\hline & & & $\begin{array}{c}\text { Alto de } \\
\text { Ventanas }\end{array}$ & $\begin{array}{l}\text { Alto La } \\
\text { Llorona }\end{array}$ & $\begin{array}{c}\text { Alto Topacio -Río } \\
\text { Azufrado }\end{array}$ & El Sifón & Media & $\begin{array}{c}\text { Desviación } \\
\text { estándar }\end{array}$ \\
\hline \multirow{3}{*}{ Emplazamiento } & \multicolumn{2}{|c|}{ Espesor (m) } & 108 & 50 & 25 & 70 & 63,3 & 35,1 \\
\hline & \multicolumn{2}{|c|}{ Altura (m) } & 10 & 14 & 10 & 9 & 10,8 & 2,2 \\
\hline & \multicolumn{2}{|c|}{ Morfología } & Lobular & Lobular & Lobular & Lobular & & \\
\hline \multirow{2}{*}{ Espesor de facies } & \multirow{2}{*}{\multicolumn{2}{|c|}{$\begin{array}{c}\text { Entabladura (m) } \\
\text { Columnata (m) }\end{array}$}} & 15 & 6 & 0 & 0 & 5,3 & 7,1 \\
\hline & & & 20 & 8 & 10 & 9 & 11,8 & 5,6 \\
\hline \multirow{9}{*}{ Columnas } & \multicolumn{2}{|c|}{ Media } & 2,7 & 2,2 & 1,8 & 5,7 & 3,1 & 1,8 \\
\hline & \multirow{2}{*}{ Altura (m) } & Mediana & 2,5 & 2,0 & 1,6 & 5,0 & 2,8 & 1,5 \\
\hline & & Desviación estándar & 0,7 & 1,1 & 0,4 & 1,3 & 0,7 & 0,4 \\
\hline & \multirow{3}{*}{ Espesor (m) } & Media & 1,5 & 1,1 & 0,4 & 2,2 & 1,3 & 0,8 \\
\hline & & Mediana & 1,6 & 1,0 & 0,4 & 2 & 0,8 & 0,7 \\
\hline & & Desviación estándar & 0,3 & 0,3 & 0,1 & 0,7 & 0,2 & 0,2 \\
\hline & \multirow{3}{*}{ Inclinación $\left({ }^{\circ} \mathrm{E}\right)$} & Media & 78 & 75,7 & 84,3 & 55 & 73,3 & 12,7 \\
\hline & & Mediana & 80 & 75 & 85 & 60 & 73,7 & 10,8 \\
\hline & & Desviación estándar & 5,1 & 8,2 & 3,6 & 7,5 & 5,5 & 2,1 \\
\hline \multirow{4}{*}{$\begin{array}{c}\text { Espacio entre las } \\
\text { columnas }\end{array}$} & \multirow{3}{*}{ Espesor (mm) } & Media & 0,8 & 2,6 & 1,9 & 2,1 & 1,8 & 0,8 \\
\hline & & Mediana & 0,8 & 2,0 & 2,0 & 2,1 & 1,7 & 0,6 \\
\hline & & Desviación estándar & 0,2 & 1,7 & 0,8 & 1,5 & 1,1 & 0,7 \\
\hline & \multicolumn{2}{|c|}{ Relleno } & Lodo & $\begin{array}{l}\text { Limo y } \\
\text { arcilla } \\
\end{array}$ & Agua y lodo & $\begin{array}{c}\text { Agua, lodo y } \\
\text { arcilla } \\
\end{array}$ & & \\
\hline \multirow{6}{*}{ Estrías } & \multirow{3}{*}{ Espesor (cm) } & Media & 5,2 & 8,1 & 22 & 13,8 & 12,27 & 7,41 \\
\hline & & Mediana & 4,0 & 8,0 & 22,5 & 14,0 & 12,13 & 8,05 \\
\hline & & Desviación estándar & 3,3 & 3,2 & 10,1 & 5,1 & 5,42 & 3,24 \\
\hline & \multirow{3}{*}{ Inclinación $\left({ }^{\circ} \mathrm{W}\right)$} & Media & 22,4 & 24,2 & 14,1 & 37,1 & 24,45 & 9,51 \\
\hline & & Mediana & 10 & 25 & 14,5 & 35 & 21,13 & 11,18 \\
\hline & & Desviación estándar & 16,3 & 7,2 & 2,5 & 6,3 & 8,08 & 5,84 \\
\hline \multirow{7}{*}{ Polígonos } & \multicolumn{2}{|c|}{ Número de lados } & 4 & 4 & 4 & 4 & 4,00 & \\
\hline & \multirow{3}{*}{$\begin{array}{l}\text { Longitud de lados } \\
\qquad(\mathrm{cm})\end{array}$} & Media & 20,0 & 122,4 & 32,7 & 231,3 & 101,58 & 97,73 \\
\hline & & Mediana & 20,0 & 120,0 & 35,0 & 235,0 & 102,50 & 98,70 \\
\hline & & Desviación estándar & 12,0 & 58,6 & 17,4 & 53,5 & 35,38 & 24,05 \\
\hline & \multirow{3}{*}{ Diámetro (m) } & Media & 1,5 & 1,5 & 0,4 & 2,6 & 1,50 & 0,87 \\
\hline & & Mediana & 1,5 & 1,5 & 0,5 & 2,5 & 1,07 & 0,82 \\
\hline & & Desviación estándar & 0,3 & 1,1 & 0,2 & 0,7 & & \\
\hline
\end{tabular}


En la Figura 7 se comparan gráficamente las principales dimensiones de columnas (altura, ancho, diámetro) entre los cuatro sitios a través de diagramas de caja y bigotes en donde se aprecian tanto la dispersión como la simetría de los datos (el mínimo y máximo dato se unen a la caja a través de las líneas laterales o "bigotes") con base en la mediana (indicada por la línea divisoria de cada caja) la cual no se afecta por valores atípicos como algunos que se presentan en esta muestra.

Las columnas en el sitio El Sifón exhiben mayores dimensiones de altura y ancho, mientras que las del Alto Topacio - Río Azufrado son las más pequeñas y su proporción alto:ancho muestra que son significativamente más altas que anchas. Los sitios Alto de Ventanas y Alto La Llorona, que corresponden al mismo emplazamiento, conservan casi la misma proporción alto:ancho en las columnas y sus dimensiones son las más similares. Además, allí también se aprecia la similitud entre las dimensiones del diámetro de los polígonos y el ancho de las columnas, sin embargo, en el caso del sitio Alto La Llorona, la dimensión del diámetro de los polígonos es levemente mayor que en el Alto de Ventanas, mientras que el ancho de las columnas es mayor para el Alto de Ventanas que para el Alto La Llorona. En cuanto a la distribución de los datos, el sitio que muestra sus datos más dispersos es El Sifón, que además es el que mayor número de datos tiene y sus dimensiones son las más grandes (Figura 7).
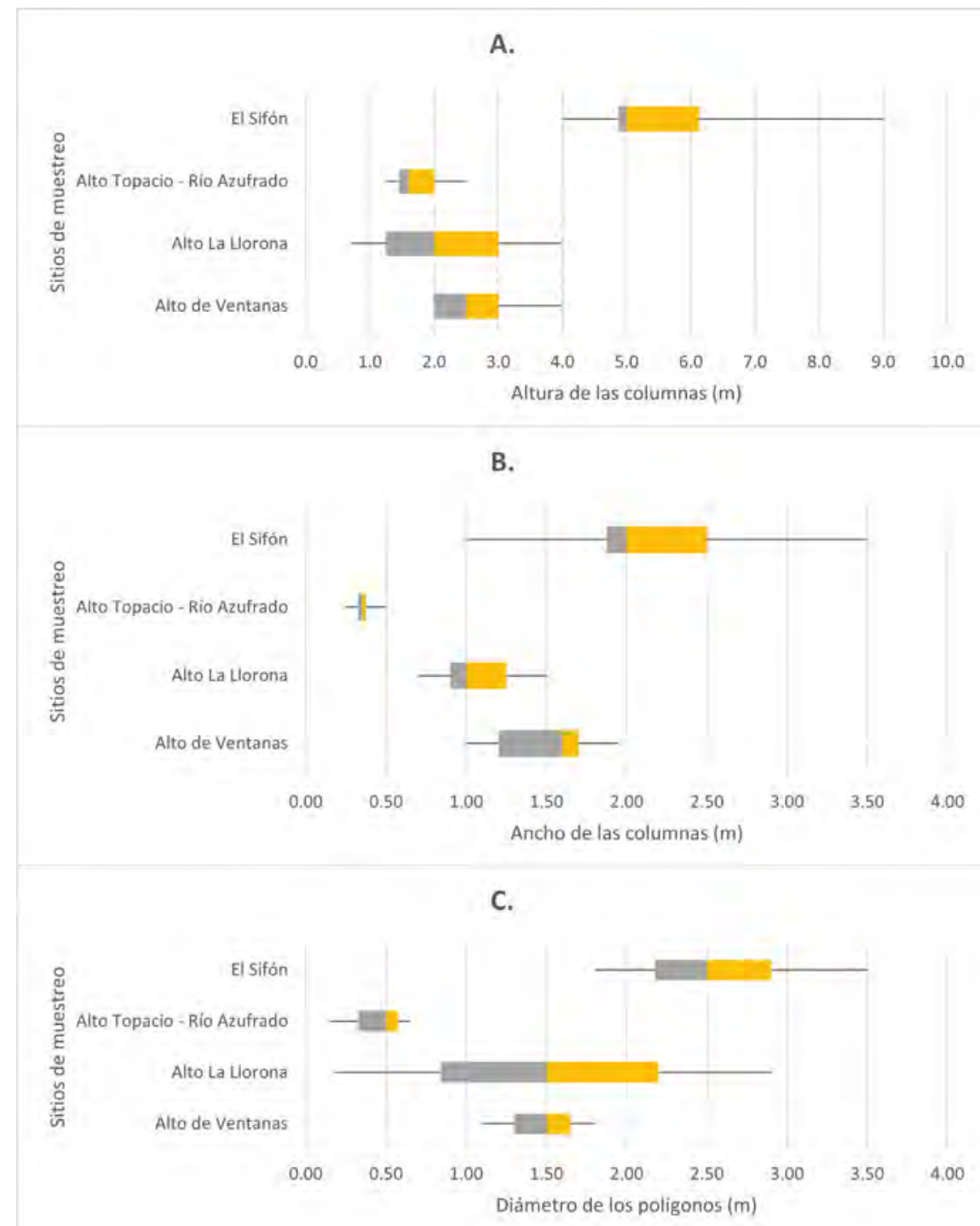

Figura 7. Diagramas de caja y bigotes de las dimensiones de las columnas en los sitios de muestreo. A. Altura de las columnas. B. Ancho de las columnas. C. Diámetro de los polígonos. 
Además, al notar que el sitio que mayores datos tiene es el que presenta mayores dimensiones, se revisaron los datos obtenidos y se identificó que el número de datos no ha afectado el valor de la mediana y por tanto no se hace aparentemente más grande por el hecho de tener más datos, lo cual se puede apreciar en el diagrama de caja y bigotes, donde se observa que la mayoría de los datos de este sitio (ilustrado como la caja), corresponden a valores superiores que los de los demás.

En la Figura 8 se compara la mediana y de forma general, la distribución de los datos de las dimensiones del espesor de las estrías observadas en algunas caras de columnas en cada sitio. En este caso, las estrías más anchas son las del sitio Alto Topacio - Río Azufrado, sitio que a su vez presenta las columnas más pequeñas (Figura 7) y que según el diagrama de caja y bigotes presenta la mayor dispersión en los datos. Sin embargo, contrario a lo que sucedía en las anteriores dimensiones comparadas, no es el sitio Alto Topacio - Río Azufrado el que más datos tiene, por lo que se ratifica que este no es un factor incluyente en lo observado en los diagramas o en las medidas de tendencia central de cada sitio. Las siguientes estrías en tamaño son las del sitio El Sifón, que corresponden a las columnas más grandes.

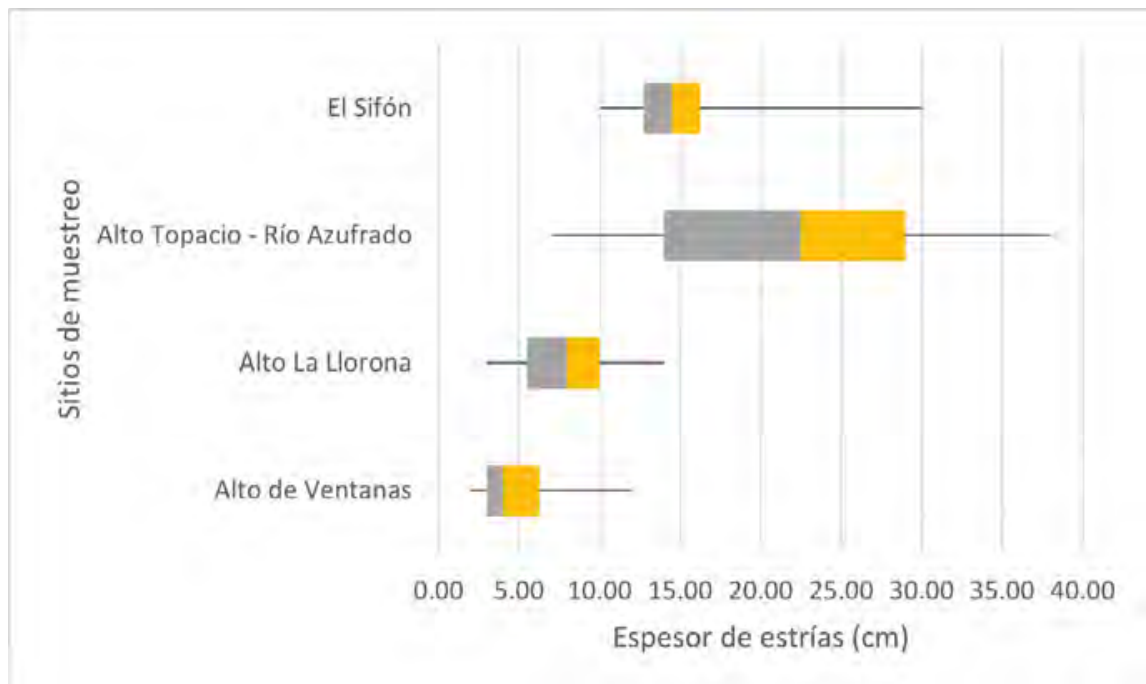

Figura 8. Diagrama de caja y bigotes con el espesor de las estrías en los sitios de muestreo.

\section{Análisis petrográfico}

Se analizaron cuatro secciones delgadas, una por cada sitio, extraída de la muestra de mano más fresca de cada localidad, las cuales cuentan con cristales de plagioclasa (oligoclasa y andesina), hornblenda, clinopiroxeno y otros minerales (Tabla 3). Los cristales de plagioclasa son euhedrales de hasta $3 \mathrm{~mm}$, con macla polisintética, zonación, e intercrecimiento de clinopiroxeno, con 45 - 58 vol.\% de masa fundamental vítrea, las cuales se clasifican como fenoandesitas vítricas y fenoandesitas vítreas.

Tabla 3. Resumen de características petrográficas.

\begin{tabular}{|c|c|c|c|c|c|}
\hline & & $\begin{array}{c}\text { Alto } \\
\text { Ventanas } \\
\end{array}$ & $\begin{array}{l}\text { Alto La } \\
\text { Llorona } \\
\end{array}$ & $\begin{array}{c}\text { Alto Topacio - Río } \\
\text { Azufrado } \\
\end{array}$ & El Sifón \\
\hline \multirow{2}{*}{$\begin{array}{l}\text { Tamaños } \\
\text { absolutos }\end{array}$} & Matriz (mm) & $<0,05$ & $<0,05$ & $<0,05$ & $<0,05$ \\
\hline & Fenocristales $(\mathrm{mm})$ & 2,2 & 3,5 & 3,2 & 2,9 \\
\hline \multicolumn{2}{|c|}{ Porcentaje matriz } & $45 \%$ & $38 \%$ & $57,5 \%$ & $48,7 \%$ \\
\hline & Material desvitrificado & $33 \%$ & $25 \%$ & $78,8 \%$ & $36,2 \%$ \\
\hline & Microlitos & $67 \%$ & $75 \%$ & $21,2 \%$ & $63,8 \%$ \\
\hline \multicolumn{2}{|c|}{ Porcentaje fenocristales } & $55 \%$ & $62 \%$ & $42,5 \%$ & $51,3 \%$ \\
\hline
\end{tabular}


Continuación Tabla 3.

\begin{tabular}{|c|c|c|c|c|c|}
\hline & & $\begin{array}{c}\text { Alto } \\
\text { Ventanas }\end{array}$ & $\begin{array}{l}\text { Alto La } \\
\text { Llorona }\end{array}$ & $\begin{array}{c}\text { Alto Topacio - Río } \\
\text { Azufrado }\end{array}$ & El Sifón \\
\hline & Plagioclasa & $69 \%$ & $59 \%$ & $57,5 \%$ & $74,8 \%$ \\
\hline & Cuarzo & $0 \%$ & $0 \%$ & $0 \%$ & $4 \%$ \\
\hline & Feldespato alcalino & $0 \%$ & $0 \%$ & $0 \%$ & $0 \%$ \\
\hline & Biotita & $9,5 \%$ & $8 \%$ & $12,5 \%$ & $5,7 \%$ \\
\hline & Hornblenda & $11 \%$ & $18 \%$ & $16,5 \%$ & $12,5 \%$ \\
\hline & Clinopiroxenos & $7 \%$ & $12 \%$ & $8,5 \%$ & $2 \%$ \\
\hline & Olivino & $3,5 \%$ & $3 \%$ & $5 \%$ & $1 \%$ \\
\hline \multirow[t]{4}{*}{ Normalización } & Total QAPF & $69 \%$ & $59 \%$ & $58 \%$ & $79 \%$ \\
\hline & Plagioclasa & $100 \%$ & $100 \%$ & $100 \%$ & $94,92 \%$ \\
\hline & Cuarzo & $0,0 \%$ & $0,0 \%$ & $0 \%$ & $5,08 \%$ \\
\hline & Feldespato alcalino & $0,0 \%$ & $0,0 \%$ & $0 \%$ & $0 \%$ \\
\hline Índice de Color & & $31 \%$ & $41 \%$ & $42 \%$ & $21,2 \%$ \\
\hline \multirow[b]{2}{*}{ Plagioclasa } & Tamaño de cristales $(\mathrm{mm})$ & 2,2 & 3,5 & 3,2 & 2,9 \\
\hline & $\begin{array}{c}\text { Contenido Anortita } \\
\text { (\%An) }\end{array}$ & 33 & 30 & 23 & 25 \\
\hline
\end{tabular}

Según contenido normalizado de QAPF, estas muestras se encuentran en el rango de andesitas y basaltos, dentro de lo cual se diferencian con base en el índice de color que es alrededor de $40 \%$ e inferior, además del contenido de plagioclasas, que lleva a clasificarlas como fenoandesitas. Por otro lado, según el porcentaje de masa fundamental vítrea con el que cuenta, se nombran fenoandesitas vítricas, excepto la muestra de
El Sifón, que sobrepasa el 50\% de vidrio y se clasifica como fenoandesita vítrea.

Como se observa en la Figura 9, los porcentajes de cada mineral en las diferentes muestras son similares, a excepción de la muestra de El Sifón, en la cual domina el contenido de plagioclasa y es el único sitio donde se documenta presencia de cuarzo modal.

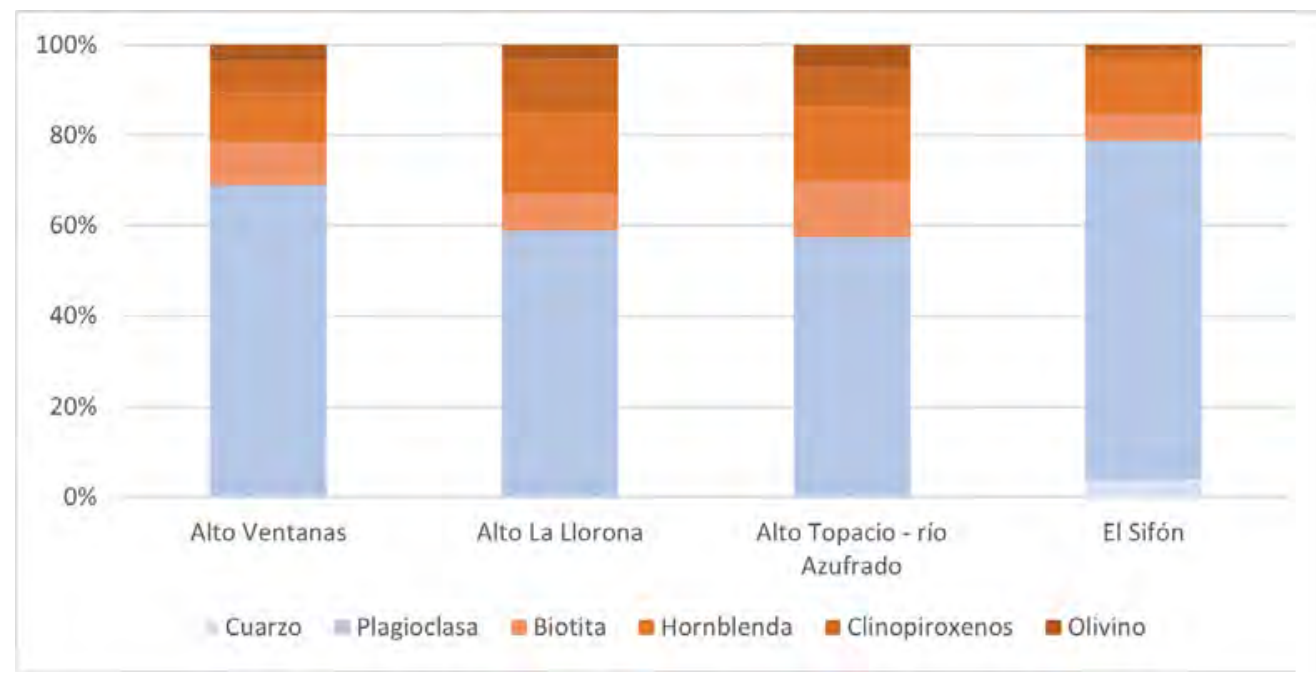

Figura 9. Composición mineralógica (no normalizada) de las muestras. 


\section{Discusión}

La mayoría de los sitios estudiados en este trabajo incluyen columnas inmaduras $y$ pobremente desarrolladas o no muestran todos los rasgos y facies típicos reportados para este tipo de estructuras (Long y Wood, 1986). Este hecho implica complejidades no muy bien entendidas en los mecanismos de enfriamiento y disipación de energía térmica y de esfuerzos dentro de los flujos de lava, o variabilidad en el proceso de emplazamiento causado por irregularidades en la superficie de flujo y modificaciones posteriores a causa de meteorización y erosión. De acuerdo con Martínez et al. (2014), un número de avalanchas y lahares han ocurrido de forma repetitiva en este flanco del VNR y la acción erosiva de estos procesos pueden haber modificado las características superficiales de los afloramientos observados. Una posible combinación de factores estaría dominando la apariencia de las estructuras, excepto en el sitio Alto Topacio - Río Azufrado, donde las columnas se observan mejor desarrolladas, más gruesas y con estrías separadas de forma regular, lo cual es compatible con un gradiente térmico moderado en el momento de formación (Grossenbacher y McDuffie, 1995), mientras en las columnas del sitio Alto La Llorona, las estrías presentan menos separación, indicando un gradiente térmico acelerado que concuerda con el contenido de vidrio y microcristales encontrado en el análisis petrográfico (Grossenbacher y McDuffie, 1995).

De otra parte, los polígonos de las columnas corresponden principalmente a cuadriláteros de diferentes configuraciones, lo que contrasta con las investigaciones de O’Reilly (1879) y Goehring y Morris (2008), en las que establecen los hexágonos como la geometría predominante en las estructuras de disyunción columnar, asociadas con el menor gasto de energía (Sánchez y Osorio, 2008), implicando que las columnas estudiadas alrededor del VNR requirieron de una alta cantidad de energía en su formación. Al tratarse en este caso de lavas densas y muy viscosas, de composición andesítica (según el análisis petrográfico de este trabajo y análisis geoquímicos de roca total de Rayo, 2012), correspondientes a flujos potentes y de menor temperatura de lo que podría ser un flujo basáltico, se interpreta que la retención de calor fue más eficiente en su interior, permitiendo almacenar y disipar la energía deformacional eficazmente para generar redes de fracturas columnares de un bajo número de lados como las observadas en los sitios estudiados.
En términos del diámetro de los polígonos en sección transversal (ancho de columnas) las estructuras del flanco NE de VNR resaltan con respecto a otros sitios descritos en Colombia por sus dimensiones medias métricas y la configuración geométrica de cuadriláteros, lo que indicaría flujos de lavas más densos y potentes que permitieron un almacenamiento y disipación de energía más eficaz que en otros emplazamientos de lavas, como el sitio La Calera, lavas del sitio Los Ataúdes, cercano a la cabecera municipal de Vijes (Valle del Cauca), o las lavas del sitio Carros de Piedra, en el área rural del municipio de Casabianca (Tolima), donde las columnas tienden a ser más delgadas y con polígonos más complejos desde cuadriláteros a heptágonos (Flórez, 2017; Calderón et al., 2017), lo que se relaciona con flujos de lava poco viscosos cuya fractura requirió una menor cantidad de energía deformacional.

\section{Conclusiones}

Se estudiaron cuatro sitios en el CVNR en los cuales se identificaron estructuras de disyunción columnar en lavas andesíticas. Los resultados y el análisis de datos permiten concluir que la geometría poligonal predominante es el cuadrilátero, ya sea de forma cuadrada o rómbica, expresando una alta energía usada en el momento de formación.

Las dimensiones promedio de las columnas estudiadas en los sitios del costado nororiental del CVNR son $3 \mathrm{~m}$ de alto y 1,3 m de ancho, con polígonos de diámetros de 1,5 m en promedio y estrías cuyo espesor es de $12,6 \mathrm{~cm}$ aproximadamente, siendo las de mayor tamaño reportadas hasta el momento en el país.

La ausencia de una de las facies en algunos de los sitios como en el Alto Topacio - Río Azufrado y El Sifón, se debe principalmente a que estas no se desarrollaron en el momento del emplazamiento, aunque no se descarta la acción de efectos de erosión o complejidades no evidentes del proceso de fractura.

Algunos rasgos de las columnas se encuentran mal desarrollados o sin desarrollar, lo que se asocia a una complejidad aun no conocida en el mecanismo de enfriamiento y disipación de la energía.

La composición de las rocas estudiadas indica un contenido significativo de vidrio (alrededor del 40 
vol.\%), lo cual indica una tasa rápida de enfriamiento, respaldado por el espacio entre las estrías, que en la mayoría de los casos es pequeño (12 cm en promedio).

\section{Agradecimientos}

Agradecemos inicialmente a la Universidad Nacional de Colombia, a los departamentos de Geociencias en la sede Bogotá y Geociencias y Medio Ambiente en la sede Medellín por hacer posible y por incentivar la realización de este tipo de trabajos de investigación. Agradecemos también a los evaluadores Hugo Murcia y Karoly Németh por aportar con su conocimiento y experiencia a la mejora de este artículo.

\section{Referencias}

Budkewitsch, P.; Robin, P.Y. (1994). Modelling the evolution of columnar joints. Journal of Volcanology and Geothermal Research, 59(3), 219-239. https://doi.org/10.1016/03770273(94)90092-2

Calderón, C.E.; Flórez, D.F.; Sánchez, J.J. (2017). Mecanismos geofísicos de formación de diaclasas columnares en rocas volcánicas: Casos de estudio en Colombia. XVI Congreso Colombiano de Geología, Santa Marta, Colombia.

Ceballos-Hernández, J.A.; Martínez-Tabares, L.M.; Valencia-Ramírez, L.G.; Pulgarín- Alzate, B.A.; Correa-Tamayo, A.M.; Narváez-Marulanda, B.L. (2020). Geological evolution of the Nevado del Ruiz Volcanic Complex. In: J. Gómez, A.O. Pinilla-Pachon (eds). The Geology of Colombia (pp. 267-296). Volume 4. Servicio Geológico Colombiano. https://doi.org/10.32685/pub. esp.38.2019.07

DeGraff, J.M.; Aydin, A. (1987). Surface morphology of columnar joints and its significance to mechanisms and direction of joint growth. GSA Bulletin, 99(5), 605-617. https://doi. org/10.1130/0016-7606(1987)99<605:SMOCJA $>2.0 . \mathrm{CO} ; 2$

Flórez, D.F. (2017). Descripción de rocas volcánicas con diaclasas columnares en varios sitios de Colombia. Trabajo de grado. Universidad Nacional de Colombia, Colombia.
Goehring, L.A.Z.; Morris, S.W. (2008). Scaling of columnar joints in basalt. Journal of Geophysical Research: Solid Earth, 113(B10). https://doi. org/10.1029/2007JB005018

Grossenbacher, K.A.; McDuffie, S.M. (1995). Conductive cooling of lava: columnar joint diameter and stria width as functions of cooling rate and thermal gradient. Journal of Volcanology and Geothermal Research, 69(1-2), 95-103. https://doi.org/10.1016/0377-0273(95)00032-1

Hetényi, G.; Taisne, B.; Garel, F.; Médard, E.; Bosshard, S.; Mattsson, H. (2012). Scales of columnar jointing in igneous rocks: field measurements and controlling factors. Bulletin of Volcanology, 74(2), 457-482. https://doi.org/10.1007/s00445011-0534-4

Jerram, D.; Petford, N. (2011). The field description of igneous rocks. Vol. 40. John Wiley \& Sons.

Levin, R.I.; Rubin, D.S. (2004). Estadística para administración y economía. Pearson.

Li, Y.; Liu, J. (2020). Late Cenozoic columnarjointed basaltic lavas in eastern and southeastern China: morphologies, structures, and formation mechanisms. Bulletin of Volcanology, 82(7). https://doi.org/10.1007/s00445-020-01397-1

Long, P.E.; Wood, B.J. (1986). Structures, textures and cooling histories of Columbia River basalt flows. GSA Bulletin, 97(9), 1144-1155. https:// doi.org/10.1130/0016-7606(1986)97<1144:STA $\mathrm{CHO}>2.0 . \mathrm{CO} ; 2$

Martínez, L.M.; Valencia, L.G.; Ceballos, J.A.; Narváez, B.L.; Pulgarín, B.A.; Correa, A.M.; Pardo, N. (2014). Geología y estratigrafía del Complejo Volcánico Nevado del Ruiz. Informe final. Servicio Geológico Colombiano.

Müller, G. (1998). Experimental simulation of basalt columns. Journal of Volcanology and Geothermal Research, 86(1-4), 93-96. https://doi.org/10.1016/ S0377-0273(98)00045-6

Murcia, H.F.; Borrero, C.A.; Németh, K. (2019). Overview and plumbing system implications of monogenetic volcanism in the northernmost Andes' volcanic province. Journal of Volcanology 
and Geothermal Research, 383, 77-87. https:// doi.org/10.1016/j.jvolgeores.2018.06.013

O’Reilly, J.P. (1879). Explanatory notes and discussion on the nature of the prismatic forms of a group of columnar basalts, Giant's Causeway. Transactions of the Royal Irish Academy, 26, 641-728.

Phillips, J.C.; Humphreys, M.C.; Daniels, K.A.; Brown, R.J.; Witham, F. (2013). The formation of columnar joints produced by cooling in basalt at Staffa, Scotland. Bulletin of Volcanology, 75(6). https://doi.org/10.1007/s00445-013-0715-4

Pollard, D.D.; Aydin, A. (1988). Progress in understanding jointing over the past century. GSA Bulletin, 100(8), 1181-1204. https://doi. org/10.1130/0016-7606(1988)100<1181:PIUJOT $>2.3 . \mathrm{CO} ; 2$

Rayo, L. (2012). Evolución geoquímica y térmica del volcán Nevado del Ruiz, Colombia. Tesis de Maestría, Universidad Nacional de Colombia, Bogotá, Colombia.

Saemundsson, K. (1970). Interglacial lava flows in the lowlands of Southern Iceland and the problem of two-tiered columnar jointing. Jokul, 20, 62-77.

Sánchez, E.; Osorio, M. (2008). Geología y petrogénesis de los prismas basálticos. Santa María Regla, Hidalgo. Revista Geociencia SGM, 2, 5-24.

Schmincke, H.U. (2004). Volcanism. Springer-Verlag.

Scrope, G.P. (1825). Considerations on volcanos. The probable causes of their phenomena, the laws which determine their march, the disposition of their products, and their connexion with the present state and past history of the globe; leading to the establishment of a new theory of Earth. Cambridge University Press.

Spry, A. (1962). The origin of columnar jointing, particularly in basalt flows. Journal of the Geological Society of Australia, 8(2), 191-216. https://doi.org/10.1080/14400956208527873

Streckeisen, A. (1979). Classification and nomenclature of volcanic rocks, lamprophyres, carbonatites, and melilitic rocks: Recommendations and suggestions of the IUGS Subcommission on the Systematics of Igneous Rocks. Geology, 7(7), 331-335. https://doi.org/10.1130/00917613(1979)7<331:CANOVR>2.0.CO;2

Thouret, J.C. (1990). Effects of the November 13, 1985 eruption on the snow pack and ice cap of Nevado del Ruiz volcano, Colombia. Journal of Volcanology and Geothermal Research, 41(1-4), 177-201. https://doi.org/10.1016/03770273(90)90088-W

Weinberger, R.; Burg, A. (2019). Reappraising columnar joints in different rock types and settings. Journal of Structural Geology, 125, 185194. https://doi.org/10.1016/j.jsg.2018.04.015

Winter, J.D. (2014). Principles of Igneous and Metamorphic Petrology. 2nd Edition. Pearson Education Limited.

Wright, H.M.; Lesti, C.; Cas, R.A.; Porreca, M.; Viramonte, J.G.; Folkes, C.B.; Giordano, G. (2011). Columnar jointing in vapor-phase-altered, non-welded Cerro Galán Ignimbrite, Paycuqui, Argentina. Bulletin of Volcanology, 73(10), 15671582. https://doi.org/10.1007/s00445-011-0524-6

Fecha de recibido: 05 de noviembre de 2020 Fecha de aprobado: 17 de marzo de 2021 